\title{
Current Trends of Intercultural Communication Research in Japan
}

\author{
Jiro TAKAI \\ (Nagoya University)
}

\begin{abstract}
Domestic research in intercultural communication has a history of less than three decades, yet a wide variety of studies have been conducted. This overview of current trends of the research in this field presents a review of studies conducted within the last decade in the areas of Japanese communication patterns, cross-cultural communication, intercultural interaction, intercultural adjustment, and intercultural communication training. Discussion of the current state of these areas are conducted from theoretical and methodological perspectives, and future directives are outlined.
\end{abstract}

\section{Introduction}

Since its advent in the 1960's, the field of intercultural communication has developed into an established discipline with its own original theories. According to Uehara (2002), there are approximately 600 universities throughout its originating country, the United States, which offer courses in intercultural communication. In comparison, it is still a fledgling field in Japan. Quite often in Japan, intercultural communication is confused with second language education, English language education in particular. This is evident from the content of the journals and conference presentations of the major academic association dealing with communication in our country. In fact, Furuta, Kume, and Hasegawa (1991) discovered in their survey that $24.6 \%$ of the faculty teaching communication identified their specialty field as either foreign language teaching or literature. In addition, the recent reformation of the former colleges of general education in our institutes of higher education resulted in foreign language and literal arts faculty being grouped into newly formed departments, often utilizing intercultural communication as a convenient label for the interdisciplinary nature of the arising departments. It is more typical than not, that these departments contain not even one faculty member with a degree in intercultural communication, or in the greater communication field for that matter.

While it is doubtful that intercultural communication is recognized as an established, and an independent academic field in Japan, there are currently at least four academic associations dedicated wholly, or in great part, toward the promotion of research in the field: Intercultural Education Society of Japan (IESJ, 異 文化間教育学会), Japan Society for Intercultural Relations (JSIR, 多文化関係学会), Society of Intercultural Education, Training and Research (SIETAR Japan, 異文 化コミュニケーション学会), and Communication Association of Japan (CAJ, 日本コミュニケーション学会). These and other organizations regularly publish four peerreviewed journals, some in both Japanese and English languages: Journal of Intercultural Communication (SIETAR), Intercultural/Transcultural Education (IESJ), Human Communication Studies (CAJ), and Intercultural Communication Studies (Intercultural Communication Institute of Kanda University of Foreign Studies). Of course, other journals in the fields of psychology, sociology, linguistics, language teaching, and anthropology sporadically feature articles dealing with the field.

Before a comprehensive review of recent trends in research on intercultural communication can be conducted, it is first necessary to define some terms. First, the issue of what constitutes "intercultural" is a perennial matter for discussion within the communication discipline. For example, Gudykunst and TingToomey (1988) distinguish between four distinct areas of intercultural communication research, categorized by the two dimensions of interpersonal-mediated, and comparative-interactive. Studies comparing interpersonal communication behavior across cultures are classified as "cross-cultural communication," while 
those comparing mediated behavior are called "comparative mass communication." Studies featuring the interaction between people of different cultures are referred to as "intercultural communication," while interaction between national governments, or organizations of differing national origins are categorized as "international communication." Therefore, in its strictest sense, the definition of intercultural communication would be limited to interpersonal communication between people of different cultures. However, there are overlaps, such as the negotiation between the leaders of two nations, which is both intercultural and international, or when the communication behaviors of people of two cultures are compared in the context of analyzing the sources of conflict in their interaction. With the above categorization in mind, this overview, based on a psychological focus, shall feature the two research areas that involve the interpersonal dimension, i.e., cross-cultural communication, and intercultural communication. It will be assumed that comparative mass communication would be better served by the field of sociology, while international communication should be encompassed within the field of international relations.

Second, the definition of "cultural" can be very arbitrary. Usually, culture is conceived of as national culture, implying international exchange. However, as Fantini (1997) notes, the current trend in the construal of intercultural communication implies culture as being not necessarily constrained by nationality, but by social groups, or co-cultures. For example, gender, race, social class, all represent distinct cultures, thus, communication between these groups also would constitute intercultural communication.

Third, this overview concerns recent trends, hence the word "recent" should be clarified. In this review, studies conducted since the last decade, i.e. 1990 , shall be the primary focus, although reference may be made to those before that. Certainly, a 12 year span could not be considered very recent, but in order to fully derive the scholarly trends, an extended history of the research is warranted.

Fourth, the overview shall mainly review studies presented in domestic arenas, but shall also subsume research conducted overseas on Japanese, primarily by Japanese scholars. It is increasingly common to find Japanese scholars seeking international forums for their research, so a review of only domestic literature would not reflect the actual extent of knowledge that is being disseminated by these researchers. Also, this is not an exhaustive overview, as it shall cover articles mainly from peer-reviewed journals, overlooking many important studies which might appear in non-refereed institutional bulletins and journals, books, and research reports.

Following the above definitions, the overview shall consist of two parts: one for research in crosscultural communication, and the other for research in intercultural communication.

\section{Research in Cross-Cultural Communication}

Research on cross-cultural communication can be classified into two categories: those from an emic perspective focusing on Japanese communication patterns without direct comparison to other cultures, and those from an etic approach comparing Japanese communication behavior to other cultures.

\section{Japanese Cultural Patterns of Communication}

The studies reviewed in this section consist of those which are decidedly emic, or culture specific in nature, i.e., laying claim to Japanese specificity in communication behaviors. Therefore, this review is exclusive of studies which have been conducted in Japan with the underlying assumption that their results are culturally universal, that is, studies which make no claim that they are examining Japanese cultural patterns.

Research on Japanese patterns of communication had reached its peak in the 1980's, when it emerged as one of the world's most powerful economies. However, due perhaps to the disillusionment toward the fall of the seemingly fail-proof economy, interest in the uniqueness, and the "magic" of the Japanese culture faded. The last decade has seen a sharp decrease in the number of these studies. Some research topics approached emically include interpersonal communication styles (Ito, 1992 ; Maeda, 2000 ; Midooka, 1990 ; Nakata, 2000 ; Okamoto, 1991 ; Takeuchi, Imahori, \& Matsumoto, 2001) ; rhetorical styles (Kakita, 1995 ; Okabe, 1990) ; interpersonal competence (Koyama, \& Kawashima, 1999 ; Miyahara, 1992, 1995 ; Ota, Takai, \& Tanaka, 1993 ; Takai \& Ota, 1994), interpersonal conflict (Imazai, \& 
Ohbuchi, 2002 ; Kino, 2000 ; Ohbuchi, \& Kitanaka, 1991 ; Ohsako, \& Takahashi, 1994 ; Saeki \& O’Keefe, 1994), communication apprehension (Keaten, Kelly, \& Pribyl, 1997 ; Pribyl, Keaten, Sakamoto, \& Koshikawa, 1998), self-disclosure (Kawano, 2000 ; Nakagawa, 2001 ; Nakagawa, in press) ; selfpresentation (Ito, 1999) ; interpersonal sensitivity (Uchida, \& Kitayama, 2001 ; Usami, 1998) ; and nonverbal behavior (Chonan, 2001 ; Kudoh, \& Matsumoto, 1996 ; Ujitani, 1998 ; Wada, 1991).

In evaluating these studies, it must be conceded that the overlying characteristic is their atheoretical nature. Very few of the studies present a systematic and empirical investigation of an original theory, nor of the validity of existing theories of Japanese communication. The existing literature consists mainly of one-shot, sporadic bits and pieces of research which are descriptive, but falling short of being predictive. It seems that the bulk of work done on the theories of the uniqueness of the Japanese had been conducted in the 1970's and the 1980's, during which there were many theories being generated.

Traditionally, this area of research has been reliant upon tenets of what is often referred to as nihon jinron, or Japanology, the theories of Japanese patterns of behavior. Launched by Benedict (1941) in her Chrysanthemum and the Sword, this area includes classic Japanology theories, such as tateshakairon (vertical society theory, forwarded by Nakane, 1970), kanjin shugiron (theory of between peopleness, formulated by Hamaguchi, 1983), amaeron (theory of interdependency, suggested by Doi, 1979), and shudanshugiron (theory of groupism, proclaimed by Yoneyama, 1981). The basis of nihonjinron is that the Japanese are a unique people, distinct from both Western and other Eastern cultures. This decades old assumption has formed the framework on which hypotheses are generated in crosscultural empirical investigations.

However, even amongst nihonjinron scholars, it has become a trend to negate this assumption, given that Japanese culture has not remained stagnant, but has evolved toward convergence with the Western world. Often called internationalization, or globalization, individualistic values have penetrated the cultural boundary, and the Japanese have become increasingly Western minded. Sugimoto and Mouer (1982) first expressed doubts about the uniqueness claim, and lately, other prominent nihonjinron scholars have followed suit in questioning the present day validity of the traditional image of the Japanese (Kumon, 1996; Inoue, 1990; Iwao, 1990; Miyanaga, 1991; Sofue, 1987).

In addition, social psychologists have recently noticed that cross-cultural studies involving the Japanese have not yielded the results expected from hypotheses based on nihonjinron. For example, Takano and Osaka (1999) found that of the 15 empirical studies they reviewed, which supposed that Japanese would be collectivistic, 14 did not reach that conclusion. Likewise, Matsumoto (1999) noted that 17 of the 18 studies he examined could not confirm this same contention. Furthermore, Matsumoto, Kudoh, and Takeuchi (1996) found that within culture variances were greater than between culture variances in individualism and collectivism tendencies in their comparison of the Japanese against the Americans, suggesting that cultural stereotypes are not valid, and an individual level analysis is warranted. In other words, culture as an independent variable is no longer a powerful explanatory factor for differences in communication behavior by themselves, but rather, they should be examined via some individual-level mediating variable. The reason for this has been attributed to multiple factors, such as cultural convergence as a result of globalization (Clammer, 1995 ; Iwao, 1990), sampling bias due to the use of students (Gudykunst, Yang, \& Nishida, 1987 ; Leung \& Iwawaki, 1988), and problems with theoretical frameworks (Matsumoto, 1999) and methodology (Takai, 1998). The supposed uniqueness of the Japanese cannot be proven without cross-cultural comparisons, and this brings us to the recent trends in cross-cultural studies in communication.

\section{Cross-Cultural Comparisons of Interpersonal Com- munication Behavior}

The 1990's were an era of dramatic advances in research involving cross-cultural comparisons. Until this period, cross-cultural studies were often based on the theoretical frameworks of high and low context cultures (Hall, 1976), or individualism-collectivism (Hofstede, 1980). Both were culture-level theories, which implied positioning a given culture on a single dimension, disregarding the underlying variance between individuals in any culture. For example, Japanese 
were known to be a high context, collectivistic culture, whereas most Western countries were assumed to be low context and individualistic. These cultural stereotypes were generalized to all of their respective people, and there was no accounting for exceptions. However, this problem was rectified with the introduction of the individual-level cultural variable of interdependent and independent self-construal (Markus \& Kitayama, 1991). This highly heuristic theory has given this area of research a brand new perspective on which to formulate hypotheses, and most crosscultural research at present make at least some mention of self-construal.

Armed with a robust theoretical framework, the most significant trend as of late in cross-cultural communication research involving Japanese has been the utilization of multiple level analyses. For example, Kim, Hunter, Miyahara, Horvath, Bresnahan, \& Yoon (1996) devised a predictive model with the $\mathrm{cul}$ tural variable of individualism-collectivism as the predictor variable, mediated by the individual variable of self-construal, predicting the outcome variable of perceived communication constraint. Similarly, Gudykunst, Matsumoto, Ting-Toomey, Nishida, Kim, and Heyman (1996), Oetzel, Ting-Toomey, Masumoto, Yokochi, Pan, Takai, and Wilcox (2001), and Stephan, Stephan, Saito, and Barnett (1998) have predicted communication styles based on similar causal models as Kim et al. (1996).

There is no doubt as to the importance of the interaction of the cultural and individual levels of individualism-collectivism on communication, but the question of which level is the better predictor remains unanswered. For example, Gudykunst et al. (1996) conclude that the individual level predictors (selfconstrual and values) were more predictive of communication styles than the cultural level (individualismcollectivism). Meanwhile, Stephan et al. (1998) found that the cultural level was more influential toward predicting emotional expression than the individual, which in their case was idiocentrism-allocentrism.

In view of these conflicting results, some problems with this new theoretical framework have been noted. Matsumoto (1999) contends that the crucial assumptions on which independent versus interdependent self-construal theory has been founded might not be sufficient, at least for explaining the particular comparison between Japanese and Americans. After conducting his review described above, he concludes that self-construal theory, in conjunction with individualism-collectivism theory, may not be adequately sensitive toward differences in psychological phenomena between Japanese and Americans. He suggests that an alternative cultural-self theory, one which is not based on individualism-collectivism, is in order, citing the example of Triandis' (1989) notion of private, public, and collective selves.

An alternative explanation for the relative failure of studies in attaining the expected cultural patterns in Japanese versus American comparisons is that an additional dimension, aside from individualismcollectivism, is required. Triandis (1995) has combined individualism-collectivism with power distance, to derive a four-category typology of horizontal individualism, vertical individualism, horizontal collectivism, and vertical collectivism. This interaction between the two cultural dimensions accounts for the two most distinguishing characteristics of Japanese communication: sensitivity to ingroup versus outgroup, and to status and power differences.

These two relational dimensions are of utmost importance in any comparison involving the Japanese. Many of the studies which had failed to attain data supporting their cultural expectations had been approached from a dispositional point of view, considering individualism-collectivism as a stable, global personality trait. This approach does not take into account the Japanese propensity to change their communication behavior according to the situation and to the relational traits of the interaction partner. Therefore, cross-cultural comparisons should be based on a causal model leading from the cultural level to the individual level, mediated by the situationalrelational level, and then to the outcome variable of communication behavior. Takai (2002) conducted three studies probing into the viability of this model in his investigation of the popular cultural stereotype of communication styles of Japanese indirectness, and American directness. He discovered that these stereotypes were not consistent across situations and interaction partners, but overall, Japanese were more discriminating toward relational intimacy, status dif- 
ferences, and situation than Americans.

So far, the trends reviewed in this genre consisted mainly of those works headed by overseas researchers. If the adoption of multilevel analyses constitute cutting edge research, the majority of domestic investigators in cross-cultural interpersonal communication may be considered as trailing behind, but this does not, by all means, imply that their research is inferior. Most studies are based on the theory of individualism-collectivism, and most pay particular attention toward the cultural equivalence of measures. A list of the topics of research conducted by domestic scholars include: communication styles (Suzuki, 1998) ; silence management (Hasegawa, \& Gudykunst, 1998) ; conflict management (Miyahara, Kim, Shin, \& Yoon, 1998 ; Ohbuchi, 1992 ; Ohbuchi, Fukushima, \& Tedeschi, 1999 ; Ohbuchi, \& Takahashi, 1994 ; Ting-Toomey, \& Kurogi, 1998) ; requesting and refusal (Saeki \& O'Keefe, 1994); apology (Sugimoto, 1997a, 1997b, 1998 ; Takaku, Weiner, \& Ohbuchi, 2001) ; criticism (Bresnahán, Shearman, Lee, Ohashi, \& Mosher, 2002) ; self-assertion (Niikura, 1999 ; Thompson, Klopf, \& Ishii, 1991) ; compliance gaining (Sueda, 1996) ; equivocation (Miyamoto-Tanaka, \& Bell, 1996) ; selfdisclosure (Asai, \& Barnlund, 1998 ; Gudykunst, Gao, Schmidt, Nishida, Bond, Leung, Wang, Barraclough, 1992) ; selfpresentation (Morisaki, 2002) ; embarrassment remediation (Imahori, \& Cupach, 1994 ; Sueda, \& Wiseman, 1992) ; facework (Sueda, 1995a, 1995b) ; intergenerational communication (Ota, Harwood, Williams, \& Takai, 2000 ; Williams, Ota, Giles, Pierson, Gallois, Ng, Lim, Ryan, Somera, Maher, Cai, \& Harwood, 1997) ; interpersonal trust (Nishishiba, \& Ritchie, 2000) ; nonverbal behavior (Kubota, 1994 ; Ujitani, 1998) ; interaction perceptions (Nishida, Hammer, \& Wiseman, 1998) ; and communication effectiveness (Gudykunst, \& Nishida, 2001).

The majority of the above research have compared the communication behaviors of Japanese to Americans, perhaps reflecting the extensive number of domestic researchers who have received academic training in these countries. While it is often taken for granted that Americans (Western, individualistic, independent self) are a perfect contrast to the Japanese (Eastern, collectivistic, interdependent self), many studies have not been able to confirm this expectation, perhaps for the reasons described previously. The elusiveness of the Japanese samples has led researchers to seek other collectivistic groups for comparison, such as Latin Americans, and other Asians, or multiple groups. For example, Gudykunst et al. (1996) have included Americans and Australians as individualists, compared to Japanese and Koreans as collectivists, while Oetzel et al. (2001) compared Americans and Germans against Japanese and Chinese. Another emerging trend is the within-Asian comparisons of Japanese to other Asian groups, such as the Chinese (Sueda, 1995a, 1995b), and Koreans (Miyahara, et al., 1996). The latter comparisons have fared just as well, if not better than Japanese to American comparisons, in generating significant differences, which demonstrates the dangers inherent in the overgeneralization of all Asian cultures as being collectivistic.

In summary, the directives for future domestically generated research in cross-cultural communication include the following: 1) use of valid theoretical frameworks on which to base hypotheses upon; 2) use of multiple level analyses in determining the influence of culture on behavior; and 3) accounting for relational and situational variables in any cross-cultural comparison.

\section{Research in Intercultural Communication}

So far, the research reviewed had not addressed the processes and outcomes of cultures in interaction with each other. Research into intercultural communication can be categorized into three groups: intercultural interaction, intercultural adjustment, and intercultural communication education and training. The following is a brief, and limited overview of the expansive list of literature available on the matter.

\section{Intercultural Interaction}

Intercultural interaction implies contact between members of two or more different cultures. While earlier research served mainly to describe the amount and nature of contact between different peoples, usually between Japanese and other nationals, the research in the last decade was better focused on the processes and consequences of interaction.

Much work has been generated on the issue of intercultural tolerance, facilitated by some special projects conducted by the Intercultural Education Society. Studies have been conducted on its conceptualization within the Japanese context (Hara, 2001 ; 
Iwano, 2002 ; Ozawa, 2001 ; Yoshitani, 2001, 2002), teaching of tolerance (Kawasaki, 2001 ; Kurachi, 2002), and tolerance toward specific groups, such as immigrants (Kojima, 2002 ; Morimoto, 2001 ; Niikura, 2002), international students (Nakayama, 2002 ; Yokobayashi, 2002), and returnee students (Ozawa, 2001). Although most of these studies are conceptual in nature, they provide solid suggestions for applicability in actual interaction settings.

Another significant development in this area is the work conducted on multicultural organizations, especially in the business sector. For example, analyses of problems in interaction between Japanese managers and local employees have been conducted in China (Nakamura, 2001), Taiwan (Wakabayashi, Chen, \& Huang, 1999), and the United States (Imazai, Ohbuchi, \& Hayashi, 2000 ; Suzuki, 1998). In addition, the corporate and resident images of Japanese and Japanese companies abroad have been investigated (Tanaka, Isaka, \& Toshima, 1991 ; Tanaka, Toshima, \& Isaka, 1993), providing much needed information toward training expatriates on competent intercultural communication with the hosts, within their specific settings. From this perspective, research involving international students had been conducted much more extensively, and often times, suggestions from these studies were applied into the corporate setting. Such generalizations are hardly as effective as applying the findings of these studies conducted specifically within business organizations, geared toward analyzing communication problems between management and workforce.

Intercultural competence has also received some due attention. Research has been conducted on its connection to intercultural literacy (Yamagishi, 1997), on specific target cultures, such as China (Funayama, 2002), on Japanese abroad (Yamamoto, 1998), and from a cognitive perspective (Nishida, Hammer, \& Wiseman, 1998). This area of research, however, suffers from its insistence on being a sender-centered concept, and fails to take into account the role of the receiver in defining competent communication.

Some of the other topics of research in the area of intercultural interaction include interethnic contact (Ono, 2000 ; Ota, 2000 ; Sekiguchi, 2001 ; Yamanouchi, 1999), third culture kids and returnees (Kanno, 2000 ; Nakanishi, 1992 ; Osanai, 1992 ; Ozawa, 2000 ; Shibuya, 2000 ; Sono, 1992)' and interaction/host perception (Gudykunst, Nishida,
Morisaki, \& Ogawa, 1999 ; Katsuya, Yamamoto, \& Sakamoto, 2001 ; Yamazaki,Kuramoto, Nakamura, \& Yokoyama, 2000 ; Yamazaki, Taira, Nakamura, \& Yokoyama, 1997).

Overall, the salient trend in the genre of intercultural interaction is that the bulk of the attention is now being paid to interaction within the corporate sector, neighborhoods, and public schools, rather than between international students and hosts. Access to data on campus has been relatively open, and international students had presented samples of convenience. However, researchers are now attempting to analyze interaction in the business world, where the quality of interaction is of utmost precedence to the success of the venture. More applied research in this form, in an area where explorative studies have prevailed, is a welcomed trend.

This area has not particularly yielded some much warranted theoretically based studies. Yamamoto (1998) analyzed Japanese intercultural interaction experiences from the viewpoint of Bennett's (1993) developmental model of intercultural sensitivity, while Suzuki (1998) conducted her study from the framework of social identity theory (Tajfel, \& Turner, 1978), but otherwise, the interactions have not been viewed from a theoretical base. Domestic researchers need to go beyond simply just describing the qualities of interactions, and direct their interests toward predicting success (or failure) in intercultural interactions. Aside from those already mentioned, interaction theories, such as anxiety-uncertainty management theory (Gudykunst, 1995), face-negotiation theory (Ting-Toomey, \& Kurogi, 1998), communication accommodation theory (Giles, Coupland, \& Coupland, 1991), and expectancy violation theory (Burgoon, 1995), provide established theoretical foundations on which intercultural interactions can be analyzed, yet these have not been adequately tested in intercultural interactions with Japanese.

\section{Intercultural Adjustment}

Perhaps intercultural adjustment is the largest category in terms of number of studies. Intercultural adjustment research was sparse until the early 1980's. The earlier research were merely descriptive in nature, i.e. probing into whether the sojourners were adjusting or not, but the more recent works center upon the processes and determinants by which they 
successfully adjust. The research characteristic to the state of the art can be found in Japan, as its scholars lead the world in theory development regarding adjustment.

The most extensive category of research has been that of the adjustment of international students. Since there has been a recent review of research involving international students (Tanaka, 1998), this review shall be restricted to research since that time. As Tanaka has explained, cutting edge research in this theme is still the function of social support networks on adjustment. Jou and Fukada (2002) have summarized their findings in a review of the effects of social support on the adjustment of Chinese students in Japan, giving directives for future research, including qualifying their expanded matching model of social support. Tanaka (2000) also provided an overview of her studies on social network effects and adjustment of international students in Japan, and it seems that these two groups of researchers have set the trend toward adjustment research in Japan. Mizuno, and Ishikuma (1998, 2000a, 2000b, 2001a, 2001b) have extended the theoretical framework of social support, focusing on the role of professional helpers within their networks. The contributions of these studies have been reflected in administrative and policy studies, such as Yokota (1999), Tsuboi (1999), and Niikura (2000).

The social support trend has expanded out from international students to other sojourner groups, such as housewives and family. Ohashi (1997), Suda (1999), Isa (2000), Shibuya (2000), and Sato (2001) have studied the adjustment patterns of sojourner housewives, and have incorporated the effects of host social networks and contact into their respective studies. The adjustment of family members of corporate expatriates, immigrants, and international students had been generally neglected until recently, and the increase in attention toward their needs has been long welcomed by the field. That might justify the lack of theoretical development in the studies of this area, as most are simply descriptive of the adjustment patterns, or are based on relatively aging theories.

In summary, domestic intercultural adjustment research has taken on a new direction with the developments in social support related theories, which have essentially caused a fad in research. While these predictive and explanatory studies have contributed much to the understanding of intercultural adjustment, a further search for the viability of a possibly stronger predictive framework is warranted. Some alternative theories might include Kim's (2000) integrative theory of cross-cultural adaptation, and contact theory from a social identity theory perspective. Intercultural Communication Education and Training

Intercultural communication education is often confused with multicultural education, international education, intercultural education, transcultural education, second language education, cultural sensitivity training, and cultural diversity training. Often times, these categories are used interchangeably, as their boundaries are somewhat vague. For the purpose of this review, the focus shall be placed upon intercultural training, whose ultimate goal is to facilitate successful and satisfactory communication between members of different cultural groups.

Domestic research on intercultural training had been sporadic, until the commencement of the publication of the Intercultural Communication Journal, the official journal of SIETAR Japan, which has finally provided an appropriate forum for intercultural training research. While the benefits of these training programs toward facilitating the adjustment of corporate expatriates are unquestionable, the concept of such training is foreign to Japanese, and their methods might not be compatible with their learning styles (Kondo, 1991, 1995). Most of the studies are descriptive of the methods used (Iwata, 1992; Komatsu, 2000 ; Mizuta, 1990 ; Takai, 1993), while a minority analyze the process of learning within such programs (Kondo, 1991, 1993), or assess the needs for them (Arimura, 2001). Theory based studies are lacking, and the few such examples include Isogai, Hayashi, and Uno's (1999) reentry program based on Bennett's (1993) developmental model, and Takai's (1993) training proposal based on the social skills-social support theory.

With this overview, it appears that this area would be better served with the following directives. First, more theory based studies are urgently required. Instead of blindly experimenting with various methods, a concrete training plan based on a theory of 
adjustment, or the attainment of intercultural sensitivity is desired. Second, there are no empirical studies probing into the effects of these training programs, and to present, there is no indication that they have any benefit to the trainees. A pre-post field experiment, consisting of training and control groups, with longitudinal follow up data on their adjustment during overseas assignment is warranted. Third, and perhaps the most basic requirement, is a systematic needs assessment of the people whom the training is intended for. There are few studies which do this, and training seems to be based on the subjective intuition and assumptions of what the researcher considers important. A needs analysis would make training much efficient, concentrating on the specific skill and cognitive deficiencies of the trainee. Finally, more attention is due toward adapting the training methods to the Japanese trainee, considering their particular learning styles, and group dynamics, so that maximum outcome can be assured from these programs.

\section{Conclusion}

This overview of recent trends in intercultural communication research is by no means exhaustive, and only gives a limited outlook of the vast variety of studies that have been conducted in Japan. The reader should be aware that there have been research areas that had been omitted, such as ethnic-intergroup contact and discrimination, intergroup communication, language attitudes, languages in contact, and psychological benefits of intercultural contact.

While the field of intercultural communication is relatively new in the domestic arena, the research generated by Japanese scholars is up to world standards, both in quantity, and quality. Because of the international nature of the researchers themselves, a large part of the studies have been written in the English language, or have been published in overseas journals, having been disseminated to the international academic society. This is one prominent feature of the field, giving its scholars special international exposure which those in other fields may not enjoy. Taken from another view, with such exposure, intercultural communication researchers are responsible for representing the high level of Japanese scholarship to world arenas.
The state of the art seems to be evolving from a field which has concentrated on descriptive and explorative studies, to one which is increasingly becoming conscious of theory building. Theory based studies, however, are usually structured upon existing theories which had been conceived in foreign cultures, and may not fully account for the particularities of Japanese intercultural interactants. Such forced etic approaches may be lacking in conceptual validity, and may give a false view of the communication performance of Japanese. Perhaps the major task of intercultural communication researchers for the next decade is the generation of original theories catered to the needs and characteristics of Japanese people.

\section{References}

Asai, A., \& Barnlund, D. C. 1998 Boundaries of the unconscious, private, and public self in Japanese and Americans: A cross-cultural comparison. International Journal of Intercultural Relations, 22, 431-452. Arimura, H. 2001 Intercultural training for sustainable human resource development: The importance of organizational context for training transfer. Journal of Intercultural Communication, 4, 125-146.

Benedict, R. 1941 The chrysanthemum and the sword. Rutland, VT: C. E. Tuttle.

Bennett, M. J. 1993 Towards ethnorelativism: A developmental model of intercultural sensitivity. In R. M. Paige (Ed.), Education for the intercultural experience. Yarmouth, MA: Intercultural Press. Pp. 21-72

Bresnahan, M. J., Shearman, S. M., Lee, S. Y., Ohashi, R., \& Mosher, D. 2002 Personal and cultural differences in responding to criticism in three countries. Asian Journal of Social Psychology, 5, 93-107.

Burgoon, J. K. 1995 Cross-cultural and intercultural applications of Expectancy Violations Theory. In R. L. Wiseman (Ed.), Intercultural communication theory. Newbury Park, CA: Sage. Pp.8-58.

Clammer, J. 1995 Difference and modernity: Social theory and contemporary Japanese society. London: Kegan Paul International.

Chonan, H. 2001 Grammatical differences between Japanese sign language, pidgin sign Japanese, and manually coded Japanese: Effects on comprehen- 
sion). Japanese Journal of Educational Psychology, 49, 417-426.

Doi, T. 1973 Anatomy of dependence. Tokyo: Kodansha International.

Fantini, A. E. 1997 A survey of intercultural communication courses. International Journal of Intercultural Relations, 21, 125-148.

Funayama, I. 2002 Intercultural competence as interactive collaboration: Intercultural communication in a Chinese-Japanese joint venture. Speech Communication Education, 15, 33-49.

Furuta, G., Kume, T., \& Hasegawa, N. 1990 Survey report on communication education in Japanese universities 1. Intercultural Communication Studies, 3, 91-115.

Giles, H., Coupland, J., \& Coupland, N. 1991 Accommodation Theory: Communication, context, and consequence. In H. Giles, J. Coupland, \& N. Coupland (Eds.), Contexts of accommodation: Developments in applied sociolinguistics. Cambridge: Cambridge University Press. Pp.1-68.

Gudykunst, W. B. 1995 Anxiety/Uncertainty Management Theory: Current status. In R. L. Wiseman (Ed.), Intercultural communication theory. Newbury Park, CA: Sage. Pp.8-58.

Gudykunst, W. B., Gao, G., Schmidt, K. L., Nishida, T., Bond, M. H., Leung, K., Wang, G., \& Barraclough, R. A. 1992 The influence of individualismcollectivism, self-monitoring, and predicted outcome value on communication in ingroup and outgroup relationships. Journal of Cross-Cultural Psychology, 23, 196-213.

Gudykunst, W.B., Matsumoto, Y., Ting-Toomey, S., Nishida, T., Kim, K., \& Heyman, S. 1996 The influence of individualism-collectivism, selfconstruals, and individual values on communication styles across cultures. Human Communication Research, 22, 51-543.

Gudykunst, W. B., \& Nishida, T. 2001 Anxiety, uncertainty, and perceived effectiveness of communication across relationships and cultures. International Journal of Intercultural Relations, 25, 55-71.

Gudykunst, W. B., Nishida, T., Morisaki, S., \& Ogawa, N. 1999 The influence of students' personal and social identities on their perceptions of interpersonal and intergroup encounters in Japan and the
United States. Japanese Journal of Social Psychology, 15, 47-58.

Gudykunst, W. B., \& Ting-Toomey, S. 1988 Culture and interpersonal communication. Newbury Park, CA: Sage.

Gudykunst, W.B., Yang, S.M., \& Nishida, T. 1987 Cultural differences in self-consciousness and selfmonitoring. Communication Research, 14, 7-34.

Hall, E. T. 1976 Beyond culture. New York: Doubleday.

Hamaguchi, E. 1983 Nihon rashisa no sai hakken (Rediscovering Japanese-likeness). Tokyo: Nihon Keizai Shinbunsha.

Hammer, M., Nishida, H., \& Wiseman, R. 1996 The influence of situational prototypes on dimensions of intercultural communication competence. Journal of Cross-Cultural Psychology, 27, 267-282.

Hara, H. 2001 Intercultural tolerance. Intercultural/Transcultural Education, 15, 4-13.

Hasegawa, T., \& Gudykunst, W. B. 1998 Silence in Japan and the United States. Journal of CrossCultural Psychology, 29, 668-684.

Hofstede, G. 1980 Culture's consequences. Beverly Hills: Sage.

Imahori, T. T., \& Cupach, W. R. 1994 A crosscultural comparison of the interpretation and management of face: U.S. American and Japanese responses to embarrassing predicaments. International Journal of Intercultural Relations, 18, 193-219. Imazai, K., \& Ohbuchi, K. 2002 Conflict resolution and procedural fairness in Japanese work organizations. Japanese Psychological Research, 44, 107-112.

Imazai, K., Ohbuchi, K., \& Hayashi, Y. 2000 Japanese employee's conflict resolution and procedural fairness in American work organizations. Japanese Association of Industrial/Organizational Psychology Journal, 13, 3-10.

Inoue, S. 1990 Nihonjinron ni omou. In T. Umehara (Ed.), Nihon to wa nan nanoka. Tokyo: NHK Books. Pp.150-160.

Isa, M. 2000 Josei no kikoku tekiou mondai no kenkyu: Ibunka juyou to kikoku tekiou mondai no jisshouteki kenkyu. Tokyo: Taga Shuppan.

Isogai, T. Y., Hayashi, Y., \& Uno, M. 1999 Identity issues and reentry training. International Journal of Intercultural Relations, 23, 493-525. 
Ito, T. 1999 Self-enhancement tendency in self and other evaluations: An examination of better-thanaverage effect. Japanese Journal of Psychology, 70, 367-374.

Ito, Y. 1992 Theories on interpersonal communication styles from a Japanese perspective: A sociological approach. In J. G. Blumler, J. M. McLeod, K. E. Rosenger, Comparatively speaking: Communication and culture across time and space. Newbury Park, CA: Sage. Pp.238-267.

Iwano, M. 2002 Internationalization of a community (the acceptance of others) and internationalization of its citizens (the acceptance of was as others). Intercultural/Transcultural Education, 16, 78-91.

Iwao, S. 1990 Recent changes in Japanese attitudes. In A.D. Romberg and T. Yamamoto (Eds.), Same bed, different dreams: America and Japan-Societies in transition. New York: Council on Foreign Relations. Pp.41-66.

Iwata, Y. 1992 Intercultural awareness training within the Japanese EFL classroom. Intercultural/ Transcultural Education, 6, 129-142.

Jou, Y. H., \& Fukada, H. 2002 Research on social support for international Chinese students in Japan. Japanese Journal of Social Psychology, 17, 150-184.

Kakita, H. 1995 The rhetoric of weddings in Japan. Human Communication Studies, 23, 81-104.

Kanno, Y. 2000 Kikokushijo as bicultural. International Journal of Intercultrual Relations, 24, 361382.

Katsuya, N., Yamamoto, N., \& Sakamoto, A. 2001 The interpersonal perception gap of Japanese native students and Asian foreign students in Japan: An experiment of female university students. Japanese Journal of Social Psychology, 17, 43-54.

Kawano, K. 2000 Correlational analysis among Japanese Self-Concealment scale, Kida's StimulusSeeking Scale, and self-reported physical symptoms. Japanese Journal of Experimental Social Psychology, 40, 115-121.

Kawasaki, S. 2001 Teaching strategies for equity pedagogy in fostering intercultural tolerance. Intercultural/Transcultural Education, 15, 69-85.

Keaten, J., Kelly, L., \& Pribyl, C. 1997 Communication apprehension in Japan: Grade school through secondary school. International Journal of Inter- cultural Relations, 21, 319-343.

Kim, M. S., Hunter, J. E., Miyahara, A., Horvath, A. M., Bresnahan, M., \& Yoon, H. J. 1996 Individual vs. culture-level dimensions of individualism and collectivism: Effects on preferred conversational styles. Communication Monographs, 63, 29-49.

Kim, Y. Y. 2000 Becoming intercultural: An integrative theory of communication and cross-cultural adaptation. New York: Corwin Press.

Kino, K. 2000 Japanese anger expression styles and their interpersonal influence. Japanese Journal of Psychology, 70, 494-502.

Kojima, A. 2002 Teacher's strategies for coping with differences and school culture: A case of a public junior high school which receive newcomer students. Intercultural/Transcultural Education, 16, 106-120.

Komatsu, Y. 2000 Cross-cultural adjustment and awareness: Pre-departure training for teachers on overseas assignment. Journal of Intercultural Communication, 4, 115-124.

Kondo, Y. 1991 Effects of age differences on small group discussion. Human Communication Studies, 19, 77-95.

Kondo, Y. 1993 Group dynamics of multicultural discussion groups: A fantasy theme analysis. Nihon Communication Kenkyusha Kaigi Proceedings, 5, 87-107.

Kondo, Y. 1995 Intercultural communication research and education: Intercultural communication education within universities. Nihon Communication Kenkyusha Kaigi Proceedings, 6, 25-27.

Koyama, S., \& Kawashima, H. 2001 Assessing communication competence: A survey on assessors and cultural factors. Intercultural Communication Studies, 13, 15-29.

Kubota, M. 1994 The listeners' responsive behaviors in process of communication: Cases of Americans and Japanese. Intercultural/Transcultural Education, 8, 59-76.

Kudoh, T., \& Matsumoto, D. 1996 Nihonjin no kanjou sekai. Tokyo: Seishin Shobo.

Kumon, S. 1996 Nihon wa honto ni ishitsu tokushu ka. In E. Hamaguchi (Ed.), Nihon bunka wa ishitsu ka. Tokyo: NHK Books. Pp.40-47.

Kurachi, A. 2002 The process of acquisition and 
development of intercultural tolerance of Japanese university students. Intercultural/Transcultural Education, 16, 49-62.

Leung, K., \& Iwawaki, S. 1988 Cultural collectivism and distributive behavior. Journal of CrossCultural Psychology, 19, 35-49.

Maeda, N. 2000 Considerations in analysis of Japanese interpersonal communication: The case of intercultural communication research. Human Communication Studies, 28, 69-86.

Matsumoto, D. 1999 Culture and self: An empirical assessment of Markus and Kitayama's theory of independent and interdependent self-construal. Asian Journal of Social Psychology, 2, 289-310.

Matsumoto, D., Kudoh, T., \& Takeuchi, S. 1996 Changing patterns of individualism and collectivism in United States and Japan. Culture and Psychology, 2, 77-107.

Midooka, K. 1990 Characteristics of Japanese-style communication. Media, Culture and Society, 12, 477-489.

Miyahara, A. 1992 Cross-cultural views on interpersonal communication competence: A preliminary proposal. Human Communication Studies, 20, 129 143.

Miyahara, A. 1995 Meta-theoretical issues in conceptualization of Japanese communication competence. Keio Communication Review, 16, 63-82.

Miyahara, A., Kim, M. S., Shin, H. C., \& Yoon, K. 1998 Conflict resolution styles among collectivistic cultures: A comparison between Japanese and Koreans. International Journal of Intercultural Relations, 22, 505-525.

Miyamoto-Tanaka, K., \& Bell, R. A. 1996 Equivocation in America and Japan: A cross-national comparison of the effects of situational conflict and status. Communication Research, 23, 261-296.

Miyanaga, K. 1991 The creative edge: Emerging individualism in Japan. New Brunswick, NJ: Transaction Publishers.

Mizuno, H., \& Ishikuma, T. 1998 A study of relationship between the preference of professional helpers of Asian international students and their adjustment. Japanese Journal of Counseling Science, 31, 1-9.

Mizuno, H., \& Ishikuma, T. 2000a Relation of soci- ological and psychological factors to preferences among professional helpers by Asian international students in Japan. Japanese Journal of Educational Psychology, 48, 165-173.

Mizuno, H., \& Ishikuma, T. 2000b Sociological and psychological factors relating to preferences among help providers of Asian international students. Japanese Journal of Educational Psychology, 49, 134-145.

Mizuno, H., \& Ishikuma, T. 2001a Recent trends and directives of social support research of international students in Japan. Japanese Journal of Community Psychology, 4, 132-143.

Mizuno, H., \& Ishikuma, T. 2001b A study of social support and adjustment of international students in Japan. Japanese Journal of Counseling Science, 34, 52-59.

Mizuta, S. 1990 Developing intercultural communication competence for Japanese college students: Cross-cultural training incorporated into English education. Speech Communication Education, 3, 1-14.

Morisaki, S. 2002 Self-presentation in Japan and the United States: The influence of self-construals and individualism-collectivism. Human Communication Studies, 30, 45-67.

Morimoto, T. 2001 Immigrants and intercultural tolerance: Immigrants, foreign residents and nationality issues. Intercultural/Transcultural Education, 15, 53-68.

Nakagawa, N. 2001 Self-disclosure of Japanese company employees: Focusing on situational approaches. Journal of Intercultural Communication, 4, 15-38.

Nakagawa, N. (in press). A study of self-disclosure of corporate workers in Korea. Intercultural/ Transcultural Education, 17.

Nakamura, A. 2001 Expatriate managers and local employees: Cases in Japanese wholly-owned ventures in and around Shenzen, China. Japanese Journal of Administrative Science, 15, 73-92.

Nakane, C. 1970 Japanese society. Tokyo: C.E. Tuttle.

Nakanishi, A. 1992 Educational issues on the crosscultural contact of overseas Japanese children. Intercultural/Transcultural Education, 6, 4-10. 
Nakata, A. 2000 The nature of equivocation in Japanese communication; From a receiver's view. Human Communication Studies, 28, 31-48.

Nakayama, A. 2002 Intercultural tolerance in the university community as examined through three case studies involving Korean graduate students. Intercultural/Transcultural Education, 16, 15-31.

Niikura, R. 1999 The psychological process underlying Japanese assertive behavior: Comparison of Japanese with Americans, Malaysians and Filipinos. International Journal of Intercultural Relations, 23, 47-76.

Niikura, R. 2000 The influence of mutual perception of personality attributes and behavior on the development of friendships between international students and their tutors. Intercultural/Trans. cultural Education, 14, 99-116.

Niikura, R. 2002 Intercultural tolerance of Japanese teachers and child care workers toward foreign school children. Intercultural/Transcultural Education, 16, 63-77.

Nishida, H., Hammer, M., \& Wiseman, R. 1998 Cognitive differences between Japanese and Americans in their perception of difficult social situations. Journal of Cross-Cultural Psychology, 29, 499-524.

Nishishiba, M., \& Ritchie, L. D. 2000 The concept of trustworthiness: A cross-cultural comparison between Japanese and U.S. business people. Applied Communication Research, 28, 347-367.

Oetzel, J., Ting-Toomey, S., Matsumoto, T., Yokoichi, Y., Pan, X., Takai, J., \& Wilcox, R. 2001 Face and facework in conflict: A cross-cultural comparison of China, Germany, Japan, and the United States. Communication Monographs, 68, 235-258.

Ohashi, T. 1997 A study on the problems of international students' families. Intercultural/Transcultural Education, 11, 156-164.

Ohbuchi, K. 1992 Nihonjin to Amerikajin no taijin kattou. In F. Watanabe, \& J. Takahashi (Eds.), Chikyu shakai jidai o dou toraeruka: Ningen kagaku no kadai to kanousei. Kyoto: Nakanishiya. Pp.1837.

Ohbuchi, K., Fukushima, O., \& Tedeschi, J. T. 1999 Cultural values in conflict management: Goal orientation, goal attainment, and tactical decision.
Journal of Cross-Cultural Psychology, 30, 51-71.

Ohbuchi, K., \& Kitanaka, T. 1991 Effectiveness of power strategies in interpersonal Conflict among Japanese students. Journal of Social Psychology, 131, 791-805.

Ohbuchi, K., \& Takahashi, Y. 1994a Cultural styles of conflict management in Japanese and Americans: Passivity, covertness, and effectiveness of strategies. Journal of Applied Social Psychology, 24, 1345-1366.

Ohsako, H., \& Takahashi, S. 1994 Effects of amae on interpersonal emotions and conflict solution strategies in interpersonal conflict situations. Japanese Journal of Experimental Social Psychology, 34, 44-57,

Okabe, R. 1990 The impact of Western rhetoric on the East: The case of Japan. Rhetorica, 8, 371-388. Okamoto, S. 1991 Expressions of request in the Japanese language: Requesters' considerations for reqestees' costs. Japanese Journal of Experimental Social Psychology, 31, 211-221.

Ono, Y. 2000 Examining intercultural exchange in local communities. Intercultural/Transcultural Education, 14, 86-98.

Osanai, H. 1992 Cross-cultural experience and human development. Intercultural/Transcultural Education, 6, 27-33.

Ota, H. 2000 Newcomer no kodomo to nihon no gakkou. Tokyo: Kokusai Shoin.

Ota, H., Harwood, J., Williams, A., \& Takai, J. 2000 A cross-cultural analysis of age identity in Japan and the United States. Journal of Multilingual and Multicultural Development, 21, 33-41.

Ota, H., Takai, J., \& Tanaka, T. 1993 Interpersonal competence: Assessing the assessment instruments. Human Communication Studies, 21, 41-63.

Ozawa, E. 2001 Two aspects of intercultural tolerance: Endurance and acceptance. Intercultural/ Transcultural Education, 15, 31-52.

Pribyl, C. B., Keaten, J. A., Sakamoto, M., \& Koshikawa, F. 1998 Assessing the cross-cultural validity of the Personal Report of Communication Apprehension scale (PRCA-24). Japanese Psychological Research, 40, 47-53.

Saeki, M., \& O'Keefe, B. J. 1994 Refusals and rejections: Designing messages to serve multiple goals. 
Human Communication Research, 21, 67-126.

Sato, Y. 2001 Social support networks of Japanese corporate wives in Western countries: Supporting intercultural adjustment for Japanese corporate wives. Human Communication Studies, 29, 11-26.

Sekiguchi, R. 2001 The identity profiles of Nikkei Brazilian students. Intercultural/Transcultural Education, 15, 162-187.

Shibuya, M. 2000 The politics of positioning in naming "returnee": Thinking possibilities in returnees' education. Intercultural/Transcultural Education, 14, 117-132.

Shibuya, Y. 2000 Examination of the Contact Hypothesis: Intercultural attitudes among Japanese company-wives in England. Japanese Journal of Social Psychology, 15, 200-211.

Sofue, T. 1987 Toshika no jidai to nihonjin. In T. Sofue (Ed.), Nihonjin wa do kawatta noka: Sengo kara gendai e. Tokyo: NHK Books. Pp.13-32.

Sono, K. 1992 Cross-cultural experiences of Japanese school children and their educational implications. Intercultural/Transcultural Education, 6, 59-65.

Stephan, C. W., Stephan, W. G., Saito, I., \& Barnett, S. H. 1998 Emotional expression in Japan and the United States: The nonmonolithic nature of individualism-collectivism. Journal of CrossCultural Psychology, 29, 728-748.

Suda, N. 1999 Issues of adjustment abroad and readjustment to their home country of Japanese spouses. Journal of Intercultural Communication, 3, 75-86.

Sueda, K. 1995a Differences in the perception of face: Chinese mien-tzu and Japanese mentsu. World Communication, 24, 23-31.

Sueda, K. 1995b Differences in communication style owing to differences in the conceptualization of mentsu. Human Communication Studies, 23, $1-13$.

Sueda, K. 1996 A cross-cultural analysis of compliance gaining: China, Japan, and the United States. Intercultural Communication Studies, 5, 1-17.

Sueda, K., \& Wiseman, R. L. 1992 Embarrassment remediation in Japan and the United States. International Journal of Intercultural Relations, 16, 159173.
Sugimoto, N. 1997a A Japan-US comparison of apology styles. Communication Research, 24, 349369.

Sugimoto, N. 1997b Apology research in Japan and the U.S.: Problematic designs in previous studies and directions for future research. Journal of Intercultural Communication, 1, 103-120.

Sugimoto, N. 1998 Norms of apology depicted in U. S. American and Japanese literature on manners and etiquette. International Journal of Intercultur. al Relations, 22, 251-276.

Sugimoto, Y., \& Mouer, R. 1982 Nihonjin wa nihonteki ka: Tokushuron o koe tajigenteki bunseki e. Tokyo: Toyo Keizai Shinposha.

Suzuki, S. 1998 In-group and out-group communication patterns in international organizations. Com munication Research, 25, 154-182.

Tajfel, H., \& Turner, J. C. 1978 An integrative theory of intergroup conflict. In W. Austin, \& S. Worchel (Eds.), The social psychology of intergroup relations. Cambridge: Cambridge University Press. Pp.33-47.

Takai, J. 1992 Intercultural social skills training. In F. Watanabe (Ed.), Gendai no esupuri: Kokusaika to ibunka kyouiku Nihon ni okeru jissen to kadai. Tokyo: Shibundo. Pp. 42-53.

Takai, J. 1998 Studying Japanese interpersonal communication. Nihon Communication Kenkyusha Kaigi Proceedings, 8, 111-140.

Takai, J. 2002 Situational and relational contexts of direct and indirect communication strategies: $A$ Japan-US cross-cultural comparison. Unpublished doctoral dissertation, University of California, Santa Barbara.

Takai, J., \& Ota, H. 1994 Assessing Japanese interpersonal communication competence. Japanese Journal of Experimental Social Psychology, 33, 224236.

Takaku, S., Weiner, B., \& Ohbuchi, K. 2001 A cross-cultural examination of the effects of apology and perspective taking on forgiveness. Journal of Language and Social Psychology, 20, 144-166.

Takano, Y., \& Osaka, E. 1999 An unsupported common view: Comparing Japan and the U.S. on individualism/collectivism. Asian Journal of Social Psychology, 2, 311-342. 
Takeuchi, S., Imahori, T., \& Matsumoto, D. 2001 Adjustment of criticism styles in Japanese returnees to Japan. International Journal of Intercultural Relations, 25, 315-327.

Tanaka, K., Isaka, Y., \& Toshima, Y. 1991 A study on the residents' opinions toward the local Japanese-owned companies in the U.S.A.: Determinants of unfavorable opinions toward Japaneseowned companies. Japanese Research in Social Psychology, 6, 112-118.

Tanaka, K., Toshima, Y., \& Isaka, H. 1993 Evaluations of the Japanese-owned corporations in European countries by the local residents: Determinants of favorable and unfavorable views of Japaneseowned corporations. Japanese Research in Social Psychology, 8, 209-221.

Tanaka, T. 1998 A review of cross-cultural adjustment of international students in Japan: From the perspective of social support network. Annual Report of Educational Psychology in Japan, 37, 143152.

Tanaka, T. 2000 Ryugakusei no social support network to social skill. Kyoto: Nakanishiya Shuppan.

Thompson, C. A., Klopf, D. W., \& Ishii, S. 1991 A comparison of social style between Japanese and Americans. Communication Research Reports, 8, $165-172$.

Ting-Toomey, S., \& Kurogi, A. 1998 Facework competence in intercultural conflict: An updated face-negotiation theory. International Journal of Intercultural Relations, 22, 187-225.

Triandis, H. C. 1989 The self and social behavior in differing cultural contexts. Psychological Review, 96, 506-520.

Triandis, H. C. 1995 Individualism and Collectivism. San Francisco: Westview.

Tsuboi, T. 1999 Intercultural exchange education between foreign students and Japanese students: A comparison with Australia. Intercultural/Trans cultural Education, 13, 60-74.

Uchida, Y., \& Kitayama, S. 2001 Development and validation of a sympathy scale. Japanese Journal of Psychology, 72, 275-282.

Uehara, A. 2002 Series kenkyushitsu shokai (8): Uehara kenkyushitsu. IDEC (Hiroshima University Graduate School of International Development and Economic Cooperation) News Letter, 11, 3.

Ujitani, E. 1998 Emotion recognition from voice across American and Japanese cultures. Journal of Intercultural Communication, 2, 117-128.

Usami, M. 1998 Discourse politeness in Japanese conversation between unacquainted people. Human Communication Studies, 26, 49-62.

Wada, M. 1991 A study of interpersonal competence: Construction of nonverbal skill scale and social skill scale. Japanese Journal of Experimental Social Psychology, 31, 49-59.

Wakabayashi, M., Chen, Z., \& Huang, K. L. 1999 Practices of critical managerial skills: A comparison among Japanese, Chinese and Taiwanese managers. Japanese Journal of Administrative Science, 13, 1-18.

Ward, C., Okura, Y., Kennedy, A., \& Kojima, T. 1998 The U-curve on trial: A longitudinal study of psychological and sociocultural adjustment during cross-cultural transition. International Journal of Intercultural Relations, 22, 277-291.

Williams, A., Ota, H., Giles, H., Pierson, H. D., Gallois, C., Ng, S. H., Lim, T. S., Ryan, E. B., Somera, L., Maher, J., Cai, D., \& Harwood, J. 1997 Young people's beliefs about intergenerational communication: An initial cross-cultural comparison. Communication Research, 24, 370-393.

Yamagishi, M. 1997 Intercultural literacy and intercultural competence. Intercultural/Trans cultural Education, 11, 37-51.

Yamamoto, S. 1998 Applying the developmental model of intercultural sensitivity in Japanese context. Journal of Intercultural Communication, 2, 77-100.

Yamanouchi, Y. 1999 The resistance of JapaneseBrazilian teenagers as the practice of everyday life: From the viewpoint of anthropology and critical pedagogy. Intercultural/Transcultural Education, 13, 89-103

Yamazaki, M., Kuramoto, N., Nakamura, S., \& Yokoyama, T. 2000 Formation of attitudes of Asian student toward the Japanese and other cultures: Understanding in terms of ethnicity. Japanese Jour nal of Educational Psychology, 48, 305-314.

Yamazaki, M., Taira, N., Nakamura, S., \& Yokoyama, T. 1997 The role of ethnicity in the 
development of the Asian students' attitudes toward Japanese and other cultures. Japanese Journal of Educational Psychology, 45, 119-128.

Yokobayashi, H. 2002 Acculturation of international students and intercultural tolerance: The trigger and its development. Intercultural/Transcultural Education, 16, 32-48.

Yokota, M. 1999 The forefront of international student support system in Japan. Intercultural/ Transcultural Education, 13, 4-18.
Yoneyama, T. 1983 Nihonjin no nakama ishiki. Tokyo: Kodansha

Yoshitani, T. 2001 Intercultural tolerance in European society: To cope with multicultural setting of society. Intercultural/Transcultural Education, 15, 14-30.

Yoshitani, T. 2002 Trigger to intercultural tolerance in the intercultural contact process. Intercultural/Transcultural Education, 16, 4-14. 